\title{
Drought and salinity affect leaf and root anatomical structures in three maize genotypes
}

\author{
Md. Injamum-Ul-Hoque ${ }^{1}$, Md. Nesar Uddin ${ }^{1}$, Md. Solaiman Ali Fakir ${ }^{1}$ and Md. Rasel ${ }^{2}$ \\ ${ }^{1}$ Department of Crop Botany and ${ }^{2}$ Department of Genetics and Plant Breeding, Bangladesh Agricultural University, \\ Mymensingh-2202, Bangladesh
}

\begin{tabular}{|c|c|}
\hline ARTICLE INFO & Abstract \\
\hline $\begin{array}{l}\text { Article history: } \\
\text { Received: } 26 \text { February } 2018 \\
\text { Accepted: } 08 \text { April } 2018\end{array}$ & \multirow{3}{*}{$\begin{array}{l}\text { Salt and drought stresses are being quite similar considered as two major constraints in maize production. } \\
\text { To explore the anatomical bases of resistance to salt and drought stresses, } 14 \text { days old seedlings of three } \\
\text { maize hybrid genotypes were subjected to salt }(100 \mathrm{mM} \mathrm{NaCl}) \text { and drought stress (equiosmotic PEG- } \\
6000) \text { under hydroponic conditions. The experiment was laid out following a completely randomized } \\
\text { design having four replicates. Root protoxylem and metaxylem thickness and root diameter were found to } \\
\text { be unaffected in both of the drought resistant genotypes in response to salt and drought stresses whereas } \\
\text { root protoxylem thickness increased ( } 33.8 \text { and } 112.8 \% \text { by salt and drought stress, respectively) in sensitive } \\
\text { genotype (BARI hybrid maize-7). Bundle sheath thickness was found to increase in response to stresses } \\
(58.4 \text { and } 59.3 \% \text { by salt and drought stress, respectively) in BARI hybrid maize-12. BARI hybrid maize- } \\
12 \text { showed unaffected response in leaf epidermal thickness, phloem area, xylem area and total leaf } \\
\text { thickness under both salt and drought stresses. }\end{array}$} \\
\hline $\begin{array}{l}\text { Keywords: } \\
\text { Salinity, PEG, protoxylem, } \\
\text { metaxylem, epidermis }\end{array}$ & \\
\hline $\begin{array}{l}\text { dence: } \\
\text { Uddin }\end{array}$ & \\
\hline
\end{tabular}

\section{Introduction}

Salinity and drought are major ecological issue in arid and semi-arid areas of the world restraining plant growth by distressing the crucial physiological processes. Maize or corn (Zea mays L.) is one of the important cereal crops that is being utilized as a source of food, feed, oil and fuel throughout the biosphere and it is moderately salt and drought stress resistant (Hussain et al., 2010). For the adaptation under stressed environment plant may modify its anatomical structures in root tissues such as thickening of the endodermis, metaxylem and protoxylem cell walls as well as increment in leaf epidermal thickness, bundle sheath thickness, xylem and phloem area (Cachorro et al., 1993; Enstone et al., 2002). Compared to endodermis, protoxylem is restrictively involved in early stages of salt stress in root tips as a proficient barrier against $\mathrm{Na}^{+}$ flow. At the cellular level, the accelerated level biosynthesis of lignin has been reported as one of the most crucial reactions that are involved in cell-wall thickening of the vascular tissues, fibers, endodermis and exodermis (Enstone et al., 2002; Naseer et al., 2012). It is suggested that maize leaf expansion under first phase of salt stress (osmotic phase) is restrictively limited due to the irreversible modification in cell wall that resists turgor driven expansion (Cramer and Bowman, 1991). Growth inhibition of maize cells under first phase of salt stress is associated with the reduced cell wall extensibility (Geilfus et al., 2011). For instance, increased cell wall thickness of vessels in sorghum (Baum et al., 2000) as well as increased thickness of Casparian strip in maize roots (Karahara et al., 2004) under salt stress have been previously reported as effective acclimation strategies to salinity.

Bangladesh Agricultural Research Institute (BARI) has recently developed two drought resistant maize genotypes (BARI hybrid maize-12 and BARI hybrid maize-13). These two genotypes can be tested to observe anatomical means of resistance against drought stress, and also to observe whether similar pattern of changes occur under first phase of salt stress. Present investigation was executed to observe differential responses of salinity and drought in three maize genotypes namely, BARI hybrid maize-7, BARI hybrid maize-12 and BARI hybrid maize-13 in a hydroponic culture. This study explored changes in leaf and root anatomical structures due to drought and first phase of salt stresses, and also genotypic differences.

\section{Materials and Methods}

\section{Plant materials and seedling growth}

Three genotypes were used in this experiment and they were collected from Bangladesh Agricultural Research Institute (BARI), Joydevpur, Gazipur. They are BARI hybrid maize-7, BARI hybrid maize-12, and BARI hybrid maize-13. Among them, the first one is a drought and salt sensitive, whereas the later two are newly released drought resistant genotypes. The caryopsis was soaked in an aerated plastic container for $24 \mathrm{~h}$. Germination took place in the dark at $25{ }^{\circ} \mathrm{C}$ in sandwich culture. The caryopses were placed between two layers of foam with oil paper moistened with water. On day 5, plants were exposed to the light. The experiment was 
conducted with hydroponic culture at hydroponic growth chamber, Plant Physiology Laboratory, Bangladesh Agricultural University, Mymensingh.

\section{Experimental layout and salt and drought simulation} The hydroponic experiment was laid out following a Completely Randomized Design (CRD) with three treatments (control with $1 \mathrm{mM} \mathrm{NaCl}$, salt treatment with $100 \mathrm{mM} \mathrm{NaCl}$ and drought treatment with equiosmotic PEG-6000) with 4 replications. As $\mathrm{C}_{4}$ photosynthesis is favoured by low level of $\mathrm{Na}^{+}$, control plants had been supplied with $1 \mathrm{mM} \mathrm{NaCl}$, and the hydroponic experiment was executed following a slightly modified protocols (Uddin et al., 2014; Uddin et al., 2016). The salt treatment started on day 14 with $25 \mathrm{mM} \mathrm{NaCl}$, and drought treatment started with equiosmotic PEG-6000. It was increased daily with $25 \mathrm{mM} \mathrm{NaCl}$ and corresponding equiosmotic PEG-6000, respectively, till a concentration of $100 \mathrm{mM} \mathrm{NaCl}$ and equiosmotic PEG6000 were reached on day 17 which was maintained till harvest on day 23. Nutrient solution was changed on every alternate day after reaching full strength concentration. After $7 \mathrm{~d}$ full exposure of salt and drought stresses, basal $2 \mathrm{~cm}$ of $5^{\text {th }}$ leaves of each genotype was isolated for leaf anatomical studies. For root anatomical studies, $1 \mathrm{~cm}$ root segments were collected after discarding $2 \mathrm{~cm}$ from root tip. Both leaf and root segments were kept in ethanol till transverse sections were made to observe the differences in anatomical structures.

\section{Root and Leaf anatomical structures measurement} Root and leaf anatomy of stressed and controlled plants were observed by light microscope (Axioscop; Carl Zeiss, Oberkochen, Germany). Here 10x and 40x of images were observed and captured. Images were processed for taking various anatomical parameters using the ZEISS ZEN digital imaging software for light microscopy. For root, metaxylem thickness and protoxylem thickness were measured from the same xylem strand. Vascular cylinder area and total root diameter were also measured. For leaf anatomy, four epidermal cells from both sides of the stomata were taken to measure epidermal thickness. In each cell three positons were selected to take thickness values and then the average was calculated. Phloem and xylem areas were measured carefully. Total leaf thickness was calculated from three sides of the leaf by measuring distance between upper and lower epidermal layers, and then average value was calculated for each sample. Metaxylem and bundle sheath thickness was measured in the same radial line.

\section{Data analysis}

The statistical analyses of the experimental data were carried out using Mini Tab 17.3 and Microsoft Excel 10.0 software packs. Statistical differences between treatments were adjusted using Fisher test.

\section{Results}

Root protoxylem thickness as influenced by salt and drought stress

Three maize hybrids exhibited significantly different responses on the root protoxylem thickness after seven days exposure to full salt and drought stress (Fig. 1 and 2 ). Both salt and equiosmotic PEG did not cause any significant change in root protoxylem thickness in BARI hybrid maize-12 and BARI hybrid maize-13. However, BARI hybrid maize-7 exhibited significant increase in root protoxylem thickness under both drought and salt stresses compared to control. Salt stress augmented root protoxylem thickness by $33.8,98.1$ and $5.9 \%$, whereas drought stress increased the same by $112.8,98.9$ and $23.6 \%$ in the root of BARI hybrid maize-7, BARI hybrid maize-12 and BARI hybrid maize-13, respectively. Relative data (ratio of protoxylem thickness between drought or salt treated plants with their respective control) for comparing drought and salt stress for each genotype reveals that drought sensitive BARI hybrid maize-7 showed significant increase in protoxylem thickness under drought stress (2.12) compared to salt stress (1.34). Other two drought resistant genotype BARI hybrid maize-12 and BARI hybrid maize-13 showed no differences in their relative responses between salt and drought stresses (Table 1). When three genotypes were compared for their relative responses to each of salt and drought stress, BARI hybrid maize-12 showed significantly higher value as compared to other two genotypes under salt stress. However, under drought, BARI hybrid maize-13 showed significantly lower relative increase in root protoxylem thickness as compared to other two genotypes (Table 1).

\section{Root metaxylem thickness as influenced by salt and drought stress}

After exposure to full salt stress $(100 \mathrm{mM} \mathrm{NaCl})$ and drought stress (equiosmotic PEG-6000), three maize hybrids showed different responses on the root metaxylem thickness of the applied stresses (Fig. 2 and 3 ). Both salt and equiosmotic PEG-6000 did not cause any significant change in root metaxylem thickness in BARI hybrid maize-12 and BARI hybrid maize-13 compared to the control. As compared to control, BARI hybrid maize-7 showed significantly higher root metaxylem thickness under drought stress, but no significant changes were noticed under salt stress. Salt stress decreased root metaxylem thickness by 0.4 and 6.5\% in BARI hybrid maize-7 and BARI hybrid maize12 , respectively, whereas it increased root metaxylem thickness by $21.2 \%$ in BARI hybrid maize- 13 . On the contrary, drought stress augmented root metaxylem thickness by 54.2 and $8.0 \%$ in BARI hybrid maize- 7 and BARI hybrid maize-13, respectively. On the other hand, drought stress decreased root metaxylem thickness by $22.6 \%$ in BARI hybrid maize-12. Relative data of metaxylem thickness (ratio between drought or salt stressed plants with their respective control) for comparing drought and salt stress reveals that drought 
sensitive BARI hybrid maize-7 showed significant increase under drought stress (1.54) compared to salt stress (0.99), whereas two drought resistant genotypes viz. BARI hybrid maize-12 and BARI hybrid maize-13 showed no significant differences in their relative responses between salt and drought stresses (Table 1). When three genotypes were compared for their relative response to either of the salt or drought stress, salt stress was found indifferent among the three genotypes. However, BARI hybrid maize-12 showed significantly lower relative thickness value as compared to the BARI hybrid maize-7 while three genotypes were compared together for relative drought responses (Table 1).

\section{Leaf epidermal thickness as influenced by salt and drought stress}

Leaf epidermal thickness differentially affected due to salt stress $(100 \mathrm{mM} \mathrm{NaCl})$ and drought stress (equiosmotic PEG-6000) (Fig. 4 and 5). Both salt and equiosmotic PEG-6000 did not cause any significant increase in leaf epidermal thickness in BARI hybrid maize-7 and BARI hybrid maize-12. On the contrary, both salt and equiosmotic PEG caused significant increase in leaf epidermal thickness of BARI hybrid maize-13 as compared to control. Salt stress increased leaf epidermal thickness by $9.8,0.4$ and $69.9 \%$, whereas drought stress augmented leaf epidermal thickness by 20.2, 7.9 and $51.3 \%$ in BARI hybrid maize-7, BARI hybrid maize-12 and BARI hybrid maize-13, respectively. Relative data (ratio of epidermal thickness between drought or salt treated plants with their respective control) for comparing drought and salt stress for each genotype reveals that all the three genotypes showed identical responses between salt and drought stresses. BARI hybrid maize-7 and BARI hybrid maize12 responded identically to each of drought and salt stresses in their relative values, whereas BARI hybrid maize-13 had significantly higher relative leaf epidermal thickness as compared to other two genotypes in each of salt and drought stresses (Table 1).

\section{Leaf bundle sheath thickness as influenced by salt and drought stress}

Salt stress and drought stress differentially changed leaf bundle sheath thickness in three maize hybrids (Fig. 5 and 6). Both salt and equiosmotic PEG did not cause any significant increase in leaf bundle sheath thickness in BARI hybrid maize-7 and BARI hybrid maize-13. On the contrary, both salt and equiosmotic PEG significantly increased in leaf bundle sheath thickness in BARI hybrid maize-12 as compared to control. Salt stress increased leaf bundle sheath thickness by $5.4,58.4$ and $99.6 \%$, whereas drought stress augmented leaf bundle sheath thickness by 7.9, 59.3 and $91.0 \%$ in BARI hybrid maize-7, BARI hybrid maize- 12 and BARI hybrid maize-13, respectively. Relative data (ratio of bundle sheath thickness between drought or salt treated plants with their respective control) for comparing drought and salt stress for each genotype reveals that each of the three genotypes showed no significant differences in their relative responses between salt and drought stresses. BARI hybrid maize-13 showed significantly higher relative increase in bundle sheath thickness as compared to the BARI hybrid maize-7 both in salt and drought stresses (Table 1).

\section{Root Diameter as influenced by salt and drought stress}

Seven days salt stress $(100 \mathrm{mM} \mathrm{NaCl})$ and drought stress (equiosmotic PEG-6000 caused different responses on root diameter depending upon the applied stresses in three maize genotypes (Fig. 2 and Table 2). Both salt and equiosmotic PEG did not cause any significant change in root diameter in BARI hybrid maize-12 and BARI hybrid maize-13. On the contrary, salt stress caused significant increase in root diameter of BARI hybrid maize-7 as compared to the control, whereas drought stress was identical to that of control in the BARI hybrid maize-7. Salt stress increased in root diameter by $20.8,0.4$ and $6.5 \%$, whereas drought stress augmented the same by $5.1,0.1$ and $0.8 \%$ in BARI hybrid maize-7, BARI hybrid maize-12 and BARI hybrid maize-13, respectively. Relative data (ratio of root diameter between drought or salt treated plants with their respective control) for comparing drought and salt stress for each genotype reveals that drought sensitive BARI hybrid maize-7 showed significant increase under salt stress (1.20) compared to drought stress (1.05), other two drought resistant genotype BARI hybrid maize-12 and drought resistant genotype BARI hybrid maize-13 showed no differences in their relative responses between salt and drought stresses. BARI hybrid maize-7 responded differentially, whereas BARI hybrid maize- 12 and BARI hybrid maize-13 responded identically to each of salt stress. All the three genotypes responded identically to each of drought stress for their relative responses (Table 1).

\section{Vascular cylinder area as influenced by salt and drought stress}

Also, vascular cylinder area had been influenced differently in three different maize hybrids under the influence of salt stress and drought stress (Table 2 and Fig. 2). Both salt and equiosmotic PEG did not cause any significant increase on area of vascular cylinder in BARI hybrid maize-7 and BARI hybrid maize-12. On the contrary, both salt and equiosmotic PEG significantly increased area of vascular cylinder in BARI hybrid maize-13 as compared to control. Salt stress decreased area of vascular cylinder by $7.7 \%$, whereas drought stress augmented the area of vascular cylinder by $3.7 \%$ in BARI hybrid maize- 7 . On the other hand, salt stress increased area of vascular cylinder by 0.4 and $8.8 \%$, whereas drought increased area of vascular cylinder by 9.2 and $5.0 \%$ in BARI hybrid maize-12 and BARI hybrid maize-13, respectively. Relative data (ratio of root vascular area between drought or salt treated plants with their respective control) for comparing 
drought and salt stress for each genotype reveals that all the genotypes showed no differences in their relative responses between salt and drought stresses. BARI hybrid maize-7 and BARI hybrid maize-13 responded differentially to the salt stress. However, all the three maize genotypes responded identically to drought stress in their relative responses (Table 1).

\section{Phloem area of leaf as influenced by salt and drought stress}

As like above parameters, three maize hybrids showed different responses on phloem area of leaf due to exposure to full salt stress and drought stress (Table 2 and Fig. 5). Equiosmotic PEG showed significant increase on phloem area in leaf of BARI hybrid maize-7 and BARI hybrid maize-13, whereas salt stress responded identical in that of two genotypes compared to control. Both salt and equiosmotic PEG did not cause any significant change on phloem area in all the three genotypes. Salt stress decreased on phloem area of leaf by $19.9 \%$, whereas drought stress augmented on phloem volume of leaf by $16.2 \%$ in BARI hybrid maize- 12 . On the other hand, salt stress increased phloem area of leaf by 4.4 and $5.0 \%$, whereas drought stress increased phloem area of leaf by 70 and $47 \%$ in BARI hybrid maize-7 and BARI hybrid maize-13, respectively. Relative data (ratio of phloem area between drought or salt treated plants with their respective control) for comparing drought and salt stress for each genotype reveals that drought sensitive BARI hybrid maize-7 showed significant increase in relative phloem area under drought stress (1.70) compared to salt stress (1.04) and BARI hybrid maize-13 showed significant increase under drought stress (1.46) compared to salt stress (1.05). Drought resistant genotype BARI hybrid maize12 showed no differences in their relative responses between salt and drought stresses. All the three genotypes responded identically to in their relative responses under salt stress. While salt stress was found identical in its response over the three genotypes, BARI hybrid maize-12 had significantly lower phloem area as compared to other two genotypes (Table 1).

Xylem area of leaf as influenced by salt and drought stress

After seven days salt stress and drought stress caused differential responses on xylem area of leaf in three maize hybrids (Table 2 and Fig. 5). Both salt and equiosmotic PEG did not show any significant change on xylem area of leaf in BARI hybrid maize-12. On the other hand, equiosmotic PEG showed significant increase in xylem area of leaf in BARI hybrid maize-7 and BARI hybrid maize-12. Salt stress increased xylem area of leaf by $20.3,8.7$ and $10.8 \%$, whereas drought stress enhanced the same by $126.3,2.4$ and $75.2 \%$ in BARI hybrid maize-7, BARI hybrid maize-12 and BARI hybrid maize-13, respectively. Relative data (ratio of xylem area between drought or salt treated plants with their respective control) for comparing drought and salt stress for each genotype reveals that drought sensitive BARI hybrid maize-7 showed significant increase in xylem area under drought stress (2.26) compared to salt stress (1.20) and BARI hybrid maize-13 showed significant increase in relative xylem area under drought stress (1.75) compared to salt stress (1.10). Again, genotypes responded identically at salt stress and differently at drought stress (Table 1).

Total leaf thickness as influenced by salt and drought stress

Three maize hybrids exhibited dissimilar responses on total leaf thickness duo to exposure to salt stress (100 $\mathrm{mM} \mathrm{NaCl}$ ) and drought stress (equiosmotic PEG-6000), (Table 2 and Fig. 5). Both salt and equiosmotic PEG did not cause any significant increase in total leaf thickness in BARI hybrid maize-7, BARI hybrid maize-12 and BARI hybrid maize-13. Salt stress increased total leaf thickness by $1.0,1.5$ and $16.2 \%$, whereas drought stress augmented the same by $14.8,4.6$ and $30.5 \%$ in BARI hybrid maize-7, BARI hybrid maize-12 and BARI hybrid maize-13, respectively, compared to control. Relative data (ratio of total leaf thickness between drought or salt treated plants with their respective control) for comparing drought and salt stress for each genotype reveals that none of the genotypes differ in their relative response values between salt and drought. Also, all the three maize genotypes responded identically to each of salt and drought stresses for their relative responses (Table 1).

\section{Leaf metaxylem thickness as influenced by salt and drought stress}

Seven days salt stress $(100 \mathrm{mM} \mathrm{NaCl})$ and drought stress (equiosmotic PEG-6000) caused different responses on leaf metaxylem thickness in three maize genotypes (Table 2 and Fig. 5). Both salt and equiosmotic PEG did not cause any significant change in leaf metaxylem thickness in BARI hybrid maize-7 and BARI hybrid maize-13. Salt and drought stress caused significant increase on leaf metaxylem thickness in BARI hybrid maize-12. On the other hand, salt stress increased leaf metaxylem thickness by $2.8 \%$ and drought stress reduced leaf metaxylem thickness by $7.0 \%$ in BARI hybrid maize-7. However, salt stress augmented leaf metaxylem thickness by 8.1 and $1.4 \%$, whereas drought stress enhanced leaf metaxylem thickness by 59.7 and $14.2 \%$ in BARI hybrid maize-12 and BARI hybrid maize-13, respectively. Relative data (ratio of leaf metaxylem thickness between drought or salt treated plants with their respective control) for comparing drought and salt stress for each genotype reveals that drought resistant BARI hybrid maize-12 showed significant increase in leaf metaxylem thickness under drought stress (1.6) compared to salt stress (1.08), whereas BARI hybrid maize-7 and BARI hybrid maize13 showed no differences in their relative responses between salt and drought stresses. All the three genotypes responded identically for their relative values under salt stress. BARI hybrid maize-12 had significantly higher relative leaf metaxylem thickness as compared to other two genotypes under drought (Table 1). 
Table 1. Effect of salt (100 $\mathrm{mM} \mathrm{NaCl})$ and drought (PEG-6000) stresses on relative value of root and leaf anatomical structures in three different maize hybrids. Each data point is the average of four replicates \pm SEM. In each group, bars sharing different letters are significantly different from each other but those sharing common letter are statistically identical at $\mathbf{P} \leq \mathbf{0 . 0 5}$

\begin{tabular}{lllll}
\hline Parameters studied & $\begin{array}{c}\text { Ratio of salt stress or drought } \\
\text { stress to control }\end{array}$ & $\begin{array}{c}\text { BARI hybrid } \\
\text { maize- }\end{array}$ & $\begin{array}{c}\text { BARI hybrid } \\
\text { maize-12 }\end{array}$ & $\begin{array}{c}\text { BARI hybrid } \\
\text { maize-13 }\end{array}$ \\
\hline Root protoxylem thickness & Salt stress: control & $1.34 \pm 0.06 \mathrm{~b}$ & $1.98 \pm 0.14 \mathrm{a}$ & $1.06 \pm 0.03 \mathrm{~b}$ \\
& Drought stress: control & $2.13 \pm 0.11 \mathrm{a}$ & $1.99 \pm 0.21 \mathrm{a}$ & $1.24 \pm 0.19 \mathrm{~b}$ \\
Root metaxylem thickness & Salt stress: control & $1.00 \pm 0.04 \mathrm{a}$ & $0.93 \pm 0.20 \mathrm{~b}$ & $1.21 \pm 0.11 \mathrm{ab}$ \\
& Drought stress: control & $1.54 \pm 0.04 \mathrm{a}$ & $0.77 \pm 0.33 \mathrm{~b}$ & $1.08 \pm 0.20 \mathrm{ab}$ \\
Root diameter & Salt stress: control & $1.21 \pm 0.07 \mathrm{a}$ & $1.00 \pm 0.05 \mathrm{~b}$ & $1.07 \pm 0.05 \mathrm{~b}$ \\
& Drought stress: control & $1.05 \pm 0.02 \mathrm{~b}$ & $1.00 \pm 0.03 \mathrm{~b}$ & $1.01 \pm 0.03 \mathrm{~b}$ \\
Vascular cylinder area & Salt stress: control & $0.92 \pm 0.06 \mathrm{a}$ & $1.00 \pm 0.03 \mathrm{ab}$ & $1.09 \pm 0.01 \mathrm{a}$ \\
& Drought stress: control & $1.04 \pm 0.07 \mathrm{ab}$ & $1.09 \pm 0.07 \mathrm{a}$ & $1.05 \pm 0.01 \mathrm{ab}$ \\
Leaf epidermal thickness & Salt stress: control & $1.10 \pm 0.01 \mathrm{~b}$ & $1.00 \pm 0.06 \mathrm{~b}$ & $1.70 \pm 0.15 \mathrm{a}$ \\
& Drought stress: control & $1.20 \pm 0.11 \mathrm{~b}$ & $1.08 \pm 0.04 \mathrm{~b}$ & $1.51 \pm 0.10 \mathrm{a}$ \\
Phloem area & Salt stress: control & $1.04 \pm 0.14 \mathrm{c}$ & $0.80 \pm 0.02 \mathrm{c}$ & $1.05 \pm 0.03 \mathrm{c}$ \\
& Drought stress: control & $1.70 \pm 0.08 \mathrm{a}$ & $1.16 \pm 0.22 \mathrm{bc}$ & $1.47 \pm 0.18 \mathrm{ab}$ \\
Xylem area & Salt stress: control & $1.20 \pm 0.14 \mathrm{c}$ & $1.09 \pm 0.02 \mathrm{c}$ & $1.11 \pm 0.21 \mathrm{c}$ \\
Total leaf thickness & Drought stress: control & $2.26 \pm 0.12 \mathrm{a}$ & $1.02 \pm 0.11 \mathrm{c}$ & $1.75 \pm 0.09 \mathrm{~b}$ \\
& Salt stress: control & $1.01 \pm 0.05 \mathrm{~b}$ & $1.02 \pm 0.04 \mathrm{~b}$ & $1.16 \pm 0.15 \mathrm{ab}$ \\
Leaf metaxylem thickness & Drought stress: control & $1.15 \pm 0.10 \mathrm{ab}$ & $1.05 \pm 0.08 \mathrm{ab}$ & $1.31 \pm 0.10 \mathrm{a}$ \\
& Salt stress: control & $1.03 \pm 0.12 \mathrm{~b}$ & $1.08 \pm 0.15 \mathrm{~b}$ & $1.01 \pm 0.06 \mathrm{~b}$ \\
Bundle sheath thickness & Drought stress: control & $0.93 \pm 0.05 \mathrm{~b}$ & $1.60 \pm 0.09 \mathrm{a}$ & $1.14 \pm 0.06 \mathrm{~b}$ \\
& Salt stress: control & $1.05 \pm 0.29 \mathrm{~b}$ & $1.58 \pm 0.08 \mathrm{ab}$ & $2.00 \pm 0.36 \mathrm{a}$ \\
& Drought stress: control & $1.08 \pm 0.11 \mathrm{~b}$ & $1.59 \pm 0.09 \mathrm{ab}$ & $1.91 \pm 0.21 \mathrm{a}$ \\
\hline
\end{tabular}

Table 2. Effect of salt stress (100 $\mathrm{mM} \mathrm{NaCl})$ and drought stress PEG-6000 on root and leaf anatomy in three different maize hybrids. Each data point is the average of four replicates \pm SEM. In each group, bars sharing different letters are significantly different from each other but those sharing common letter are statistically identical at $\mathbf{P} \leq \mathbf{0 . 0 5}$

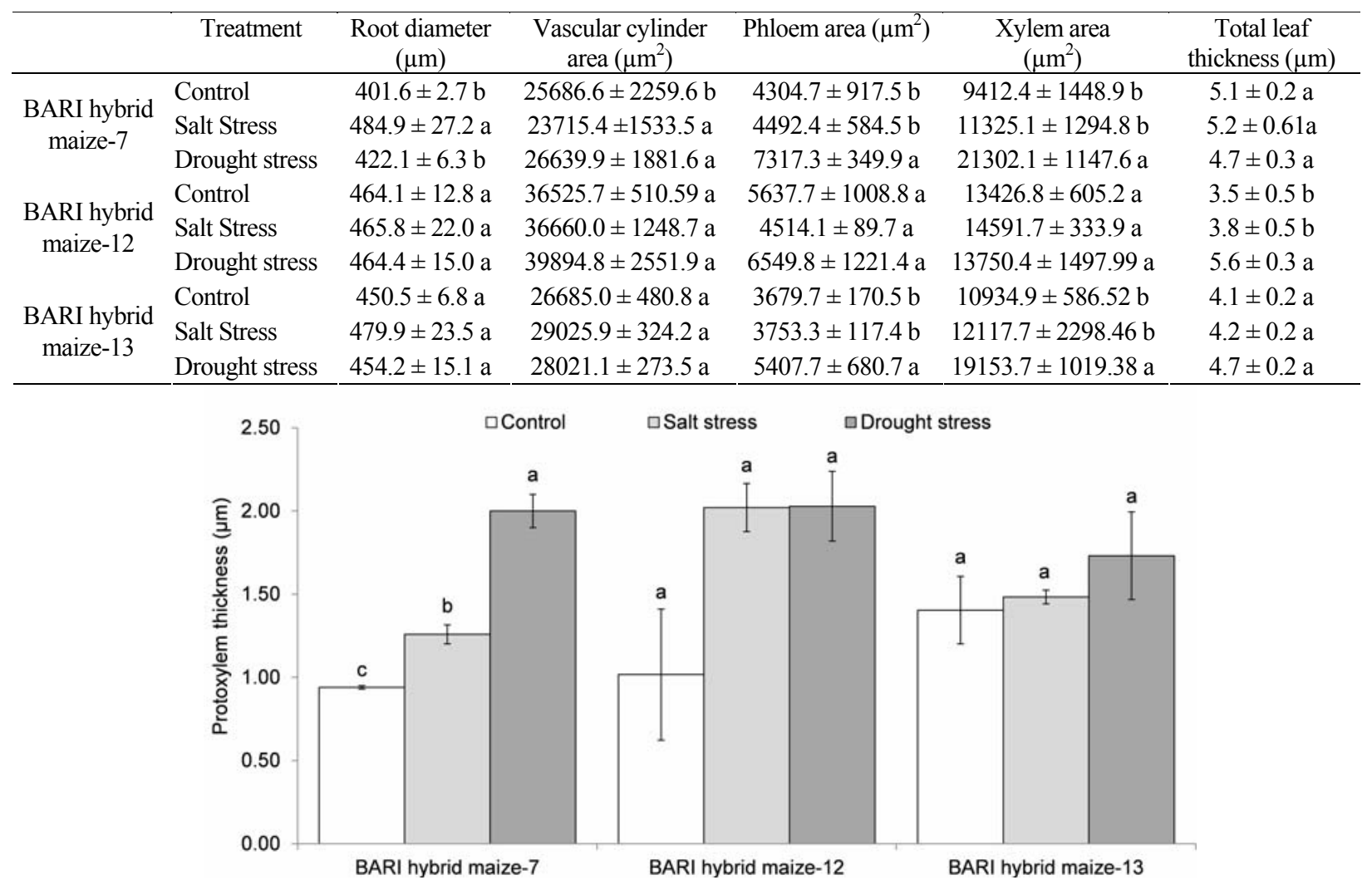

Fig. 1. Effect of salt $(100 \mathrm{mM} \mathrm{NaCl})$ and drought (equiosmotic PEG-6000) stresses on root protoxylem thickness in three different maize hybrids. Each data point is the average of four replicates \pm SEM. In each group, bars sharing different letters are significantly different from each other but those sharing common letter are statistically identical at $\mathrm{P} \leq 0.05$. 

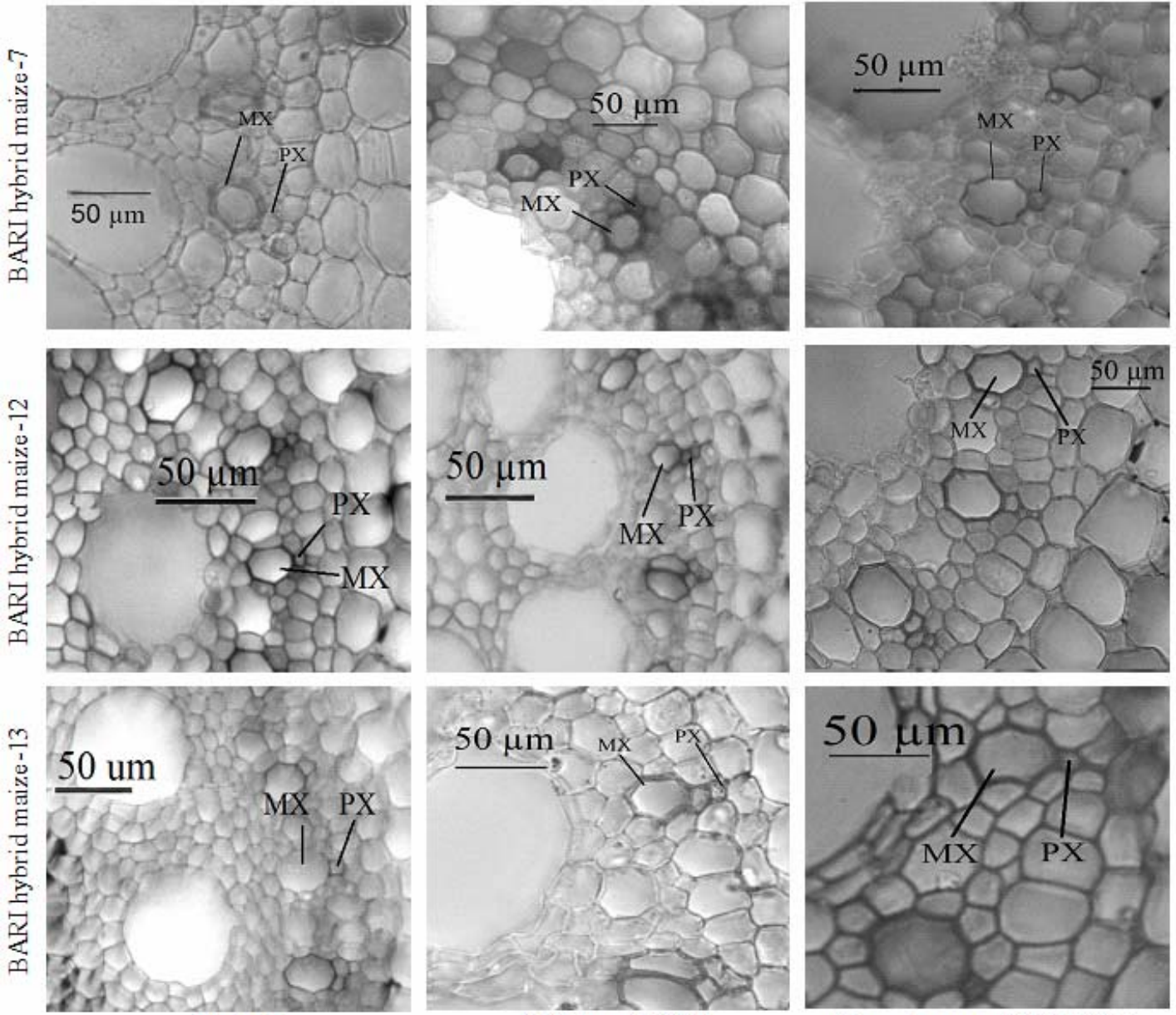

Control

Salt stress $(\mathrm{NaCl})$

Drought stress (PEG-6000)

Fig. 2. Root anatomical structures as influenced by salt (100 mM NaCl) and drought (equiosmotic PEG-6000) stresses. PX: Protoxylem, MX: Metaxylem.

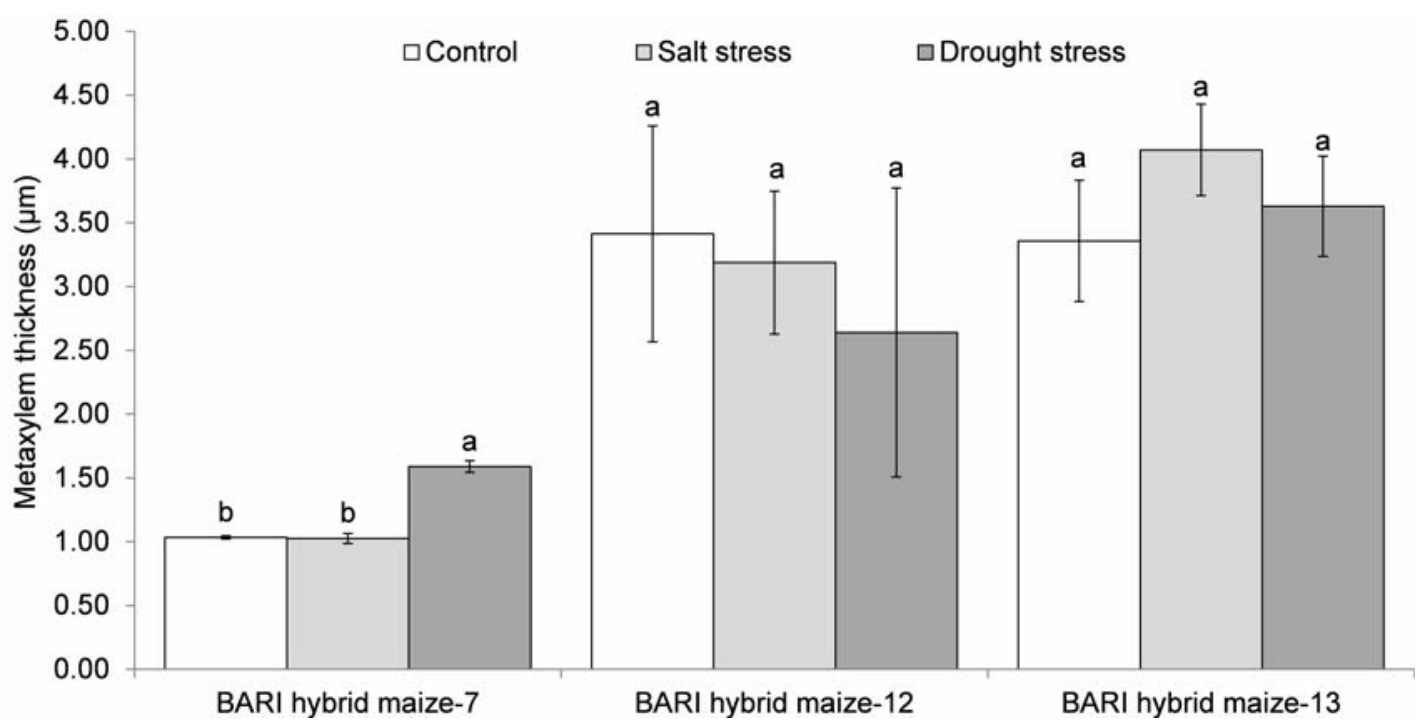

Fig. 3. Effect of salt (100 mM NaCl) and drought (equiosmotic PEG-6000) stresses on root metaxylem thickness in three different maize hybrids. Each data point is the average of four replicates \pm SEM. In each group, bars sharing different letters are significantly different from each other but those sharing common letter are statistically identical at $\mathrm{P} \leq 0.05$. 


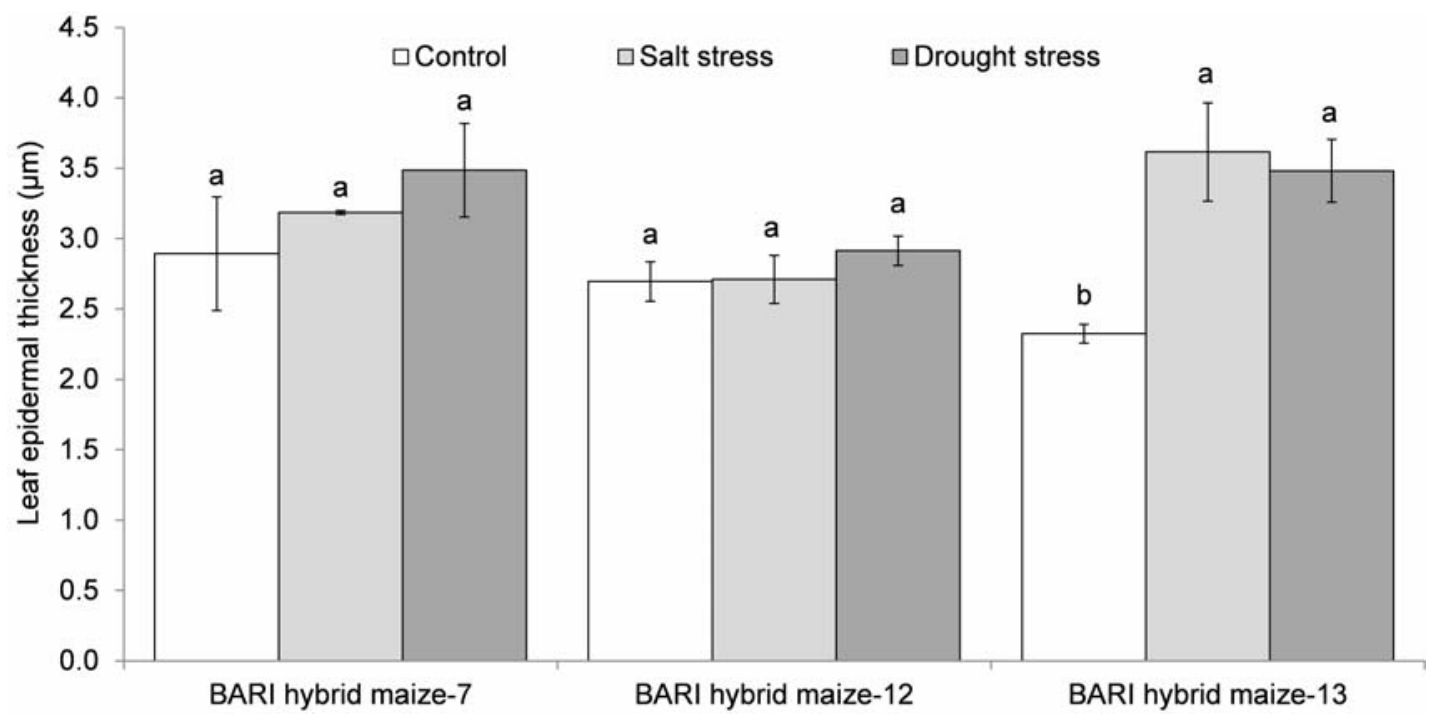

Fig. 4. Effect of salt ( $100 \mathrm{mM} \mathrm{NaCl}$ ) and drought (equiosmotic PEG-6000) stresses on leaf epidermal thickness in three different maize hybrids. Each data point is the average of four replicates \pm SEM. In each group, bars sharing different letters are significantly different from each other but those sharing common letter are statistically identical at $\mathrm{P} \leq 0.05$.
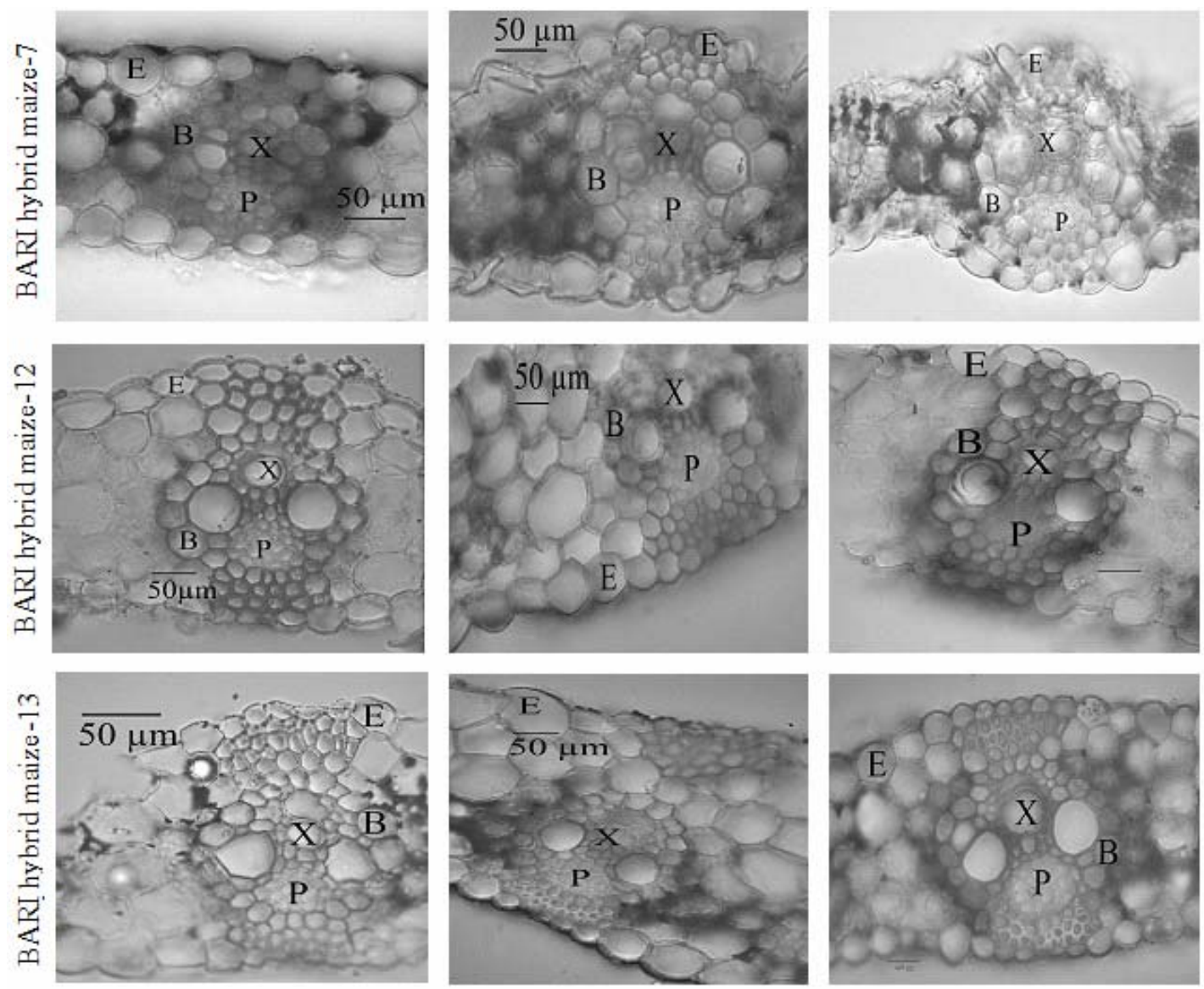

Control

Salt stress $(\mathrm{NaCl})$

Drought stress (PEG-6000)

Fig. 5. Leaf anatomical structures as influenced by salt (100 $\mathrm{mM} \mathrm{NaCl})$ and drought (equiosmotic PEG-6000) stresses. E: Epidermis, P: Phloem, X: Xylem, B: Bundle sheath 


\section{Discussion}

Anatomical attributes in maize root such as protoxylem thickness, metaxylem thickness, root diameter and area of vascular cylinder were identified to be influenced differently by salt and drought stresses. Root protoxylem and metaxylem thickness increased in the drought sensitive BARI hybrid maize-7 under drought, while these parameters were unaffected in the drought resistant genotypes BARI hybrid maize-12 and BARI hybrid maize-13 under drought. Also, increased root protoxylem thickness in BARI hybrid maize-7 under salt stress can be attributed as a strategy to defend the entrance of $\mathrm{Na}^{+}$to the root xylem structure (Hose et al., 2001). In drought resistant BARI hybrid maize-13 there was no change in root cross sectional area under drought despite significant increase in the area of root vascular cylinder. This may be an adaptive strategy of BARI hybrid maize-13 under drought. Characteristics of vascular tissues are associated with drought resistant. Changes in anatomical structure take place in plants to protect and adapt them to water stress (Makbul et al., 2011). While leaf epidermal thickness, xylem and phloem area were augmented under drought in the drought resistant genotype BARI hybrid maize-13 but unaffected in the BARI hybrid maize-12; bundle sheath and leaf metaxylem thickness were increased under drought in the drought resistant genotype BARI hybrid maize-12. Increase in xylem and phloem size and number have been reported to be associated to increase drought resistance (Das et al., 2015). Increased metaxylem thickness, phloem, and xylem area under salinity perhaps played important role in the conduction of water, photosynthates, particularly under adverse saline conditions. It was supported by previous reports in different plant species, e.g. in rice (Datta and Som, 1973), Kandelia candel (Hwang and Chen, 1995), Ziziphus cultivars (Awasthi and Pathak, 1999) and Arabidopsis thaliana (Baloch et al., 1998). The anatomical adaptive features in these two drought resistant genotypes seemed to be different. Leaves of bean, cotton and Atriplex are reported to increase in epidermal thickness with increasing salinity (Longstreth and Nobel, 1979). BARI hybrid maize-13 also confirmed the similar strategy in our experiment which showed increase in leaf epidermal thickness under salinity. The salinity-induced cell-wall rheological modifications of the epidermis emphasize a contribution of the load-bearing epidermis in restricting the expansion of the entire leaf, ultimately contributing to the salinity-induced growth reduction (Zörb et al., 2015).

\section{Conclusion}

Root protoxylem and metaxylem thickness and root diameter were found to be unaffected in both the drought resistant genotypes in either of the two stresses, while root protoxylem thickness increased in the sensitive genotype BARI hybrid maize-7 under both salt and drought stresses. In BARI hybrid maize-12, bundle sheath thickness increased under salt and drought. In contrast, leaf epidermal thickness, phloem area, xylem area and total leaf thickness were unaffected under both salt and drought stresses in this genotype. Relative response data revealed that all the genotypes responded identically between drought and salt stresses for root vascular cylinder area, thickness of leaf, leaf epidermis and bundle sheath thicknesses. In contrast, genotypes differ in their relative response between salt and drought stresses in root protoxylem and metaxylem thickness, root diameter, leaf phloem and xylem areas and leaf metaxylem thickness. Thus, it can be concluded that drought stress and first phase of salt stress are quite similar in their responses to some anatomical parameters but differ also in some other anatomical aspects in three maize hybrids studied.

\section{References}

Awasthi, O.P. and Pathak, R.K., 1999. Effect of salinity levels on survival and anatomy of four scion cultivars budded on Indian jujuba. Hort. J., 12: 53-59.

Baloch, A.H., Gates, P.J. and Baloch, V., 1998. Anatomical changes brought about by salinity in stem, leaf and root of Arabidopsis thaliana (L.) Heynh (thale cress). Sarhad J. Agric., 14: 131-142.

Baum, S.F., Tran, P.N. and Silk, W.K., 2000. Effects of salinity on xylem structure and water use in growing leaves of sorghum. New Phytol., 146(1): 119-127.

Cachorro, P., Ortiz, A., Barceló, A.R. and Cerda, A., 1993, Lignin deposition in vascular tissues of Phaseolus vulgaris roots in response to salt stress and $\mathrm{Ca}^{2+}$ ions. Phyton., 33: 33-40.

Cramer, G.R. and Bowman, D.C., 1991, Kinetics of maize leaf elongation. I: Increased yield threshold limits short-term, steady-state elongation rates after exposure to salinity. $J$. Exp. Bot., 42: 1417-1426.

Das., R., Bhagawati, K., Boro, A., Medhi, T., Medhi, B. and Bhanisanar, K., 2015. Relative performance of plant cultivars under respective water deficit adaptation strategies: A case study. Curr. World Environ., 10: 683690.

Datta, S.K. and Som, J., 1973: Note on the effect of salinity on the structural changes in the stem of rice varieties. Ind. J. Agric. Sci., 43: 614-617.

Enstone, D.E., Peterson, C.A. and Ma, F., 2002: Root endodermis and exodermis structure, function, and responses to the environment. J. Plant Growth Regul., 21(4): 335-351.

Geilfus, C.M., Zörb, C., Neuhaus, C., Hansen, T., Lüthen, H. and Mühling, K.H., 2011. Differential transcript expression of wall-loosening candidates in leaves of maize cultivars differing in salt resistance. J. Plant Growth Regul., 30(4): 387-395.

Hose, E., Clarkson, D., Steudle, E., Schreiber, L. and Hartung, W., 2001. The exodermis: a variable apoplastic barrier. J. Exp. Bot., 52(365): 2245-2264.

Hussain, K., Majeed, A., Nawaz, K. and Nisar, M.F., 2010. Changes in morphological attributes of maize (Zea mays L.) under $\mathrm{NaCl}$ salinity. American-Eurasian J. Agric. \& Environ. Sci., 8(2): 230-232.

Hwang, Y.H. and Chen, S.C., 1995. Anatomical responses in Kandelia candel L. Druce seedlings growing in the presence of different concentrations of NaCl. Bot. Bull. Acad. Sinica., 36: 181-188.

Karahara, I., Ikeda, A., Kondo, T. and Uetake, Y., 2004. Development of the Casparian strip in primary roots of maize under salt stress. Planta, 219(1): 41-47. 
Longstreth, D.J. and Nobel, P.S., 1979. Salinity effects on leaf anatomy. Plant Physiol., 63: 700-703.

Makbul, S., Saruhan Güler N., Durmus, N. and Güven, S., 2011. Changes in anatomical and physiological parameters of soybean under drought stress. Turkish J. Bot., 35: 369377.

Naseer, S., Lee, Y., Lapierre, C., Franke, R., Nawrath, C. and Geldner, N., 2012. Casparian strip diffusion barrier in Arabidopsis is made of a lignin polymer without suberin. Proc. Natl. Acad. Sci., 109(25): 10101-10106.

Uddin, M.N., Hanstein, S., Faust, F., Eitenmüler, P.T., Pitann, B. and Schubert, S., 2014. Diferulic acids in the cell wall may contribute to the suppression of shoot growth in the first phase of salt stress in maize. Phytochem., 102: 126-136.

Uddin, M.N., Hanstein, S., Leubner, R. and Schubert, S. 2013. Leaf cell-wall components as influenced in the first phase of salt stress in three maize (Zea mays L.) hybrids differing in salt resistance. J. Agron. Crop Sci., 199: 405415.

Zörb, C., Mühling, K.H., Kutschera, U. and Geilfus, C.M., 2015. Salinity stiffens the epidermal cell walls of salt-stressed maize leaves: Is the epidermis growth-restricting? PLoS ONE. 10(3): 1-15. 